\title{
The NF-KB1 is a key regulator of acute but not chronic renal injury
}

\author{
Amy Fearn ${ }^{1}$, Gerhard R Situmorang ${ }^{1,2}$, Christopher Fox ${ }^{1}$, Fiona Oakley ${ }^{1}$, Rachel Howarth ${ }^{1}$, Caroline L Wilson ${ }^{1}$, Agklinta Kiosia ${ }^{1}$, \\ Michael G Robson ${ }^{3}$, Derek A Mann ${ }^{1}$, Anna Moles ${ }^{1,4}$ and Neil S Sheerin ${ }^{\star, 1,4}$
}

The NF- $\kappa$ B family of transcription factors is important for many cellular functions, in particular initiation and propagation of inflammatory and immune responses. However, recent data has suggested that different subunits of the NF- $\kappa B$ family can suppress the inflammatory response. NF- $\kappa B 1$, from the locus nfאb1, can inhibit transcription, acting as a brake to the recognised pro-inflammatory activity of other NF- $\kappa$ B subunits. We tested the function of NF- $\kappa$ B1 in an acute (nephrotoxic serum (NTS) nephritis) and a chronic (unilateral ureteric obstruction (UUO)) model of renal injury using NF- $\kappa$ B1 (nfkb1 $1^{-l-}$ ) knockout mice. Deficiency in NF- $\kappa$ B1 increased the severity of glomerular injury in NTS-induced nephritis and was associated with greater proteinuria and persistent pro-inflammatory gene expression. Induction of disease in bone marrow chimeric mice demonstrated that the absence of NF- $K B 1$ in either bone marrow or glomerular cells increased the severity of injury. Early after UUO (day 3 ) there was more severe histological injury in the $n f k b 1^{-I-}$ mice but by day 10 , disease severity was equivalent in wild type and nfkb1 $1^{-I-}$ mice. In conclusion, NF- $\kappa$ B1 modifies acute inflammatory renal injury but does not influence chronic fibrotic injury.

Cell Death and Disease (2017) 8, e2883; doi:10.1038/cddis.2017.233; published online 15 June 2017

Glomerulonephritis (GN) is one of the leading causes of end stage renal disease (ESRD) accounting for up to $40 \%$ of ESRD in some countries. ${ }^{1}$ Many types of glomerular disease are immune-mediated, characterised by the presence of circulating autoantibodies and/or glomerular immune complex deposition $^{2}$ (anti-glomerular basement membrane disease, membranous nephropathy, lupus nephritis, and anti-neutrophil cytoplasmic antibody-associated vasculitis) and their measurement is important for diagnosis. In addition to antibodies, lymphocytes, macrophages and fluid phase mediators of inflammation, in particular complement, have been implicated in the development of glomerular injury. The autoimmune response leads to glomerular inflammation and to a progressive decline in renal function due to glomerulosclerosis and tubulointerstitial fibrosis. Activated pro-inflammatory and profibrotic mediators induce and sustain the pathophysiological events occurring within the affected kidney, including; renal vasoconstriction, immune cell infiltration, interstitial cell proliferation, accumulation of extracellular matrix proteins and eventually glomerular sclerosis and tubular atrophy. For most glomerulonephritides the trigger that initiates disease is unknown and the underlying disease mechanisms poorly understood. Current treatments for GN are nonspecific, toxic and of variable efficacy. Therefore better understanding of the biological drivers of GN is urgently needed in order to design more specific therapies.

NF-kB1 (p50) is one of the five members (RelA, RelB, c-Rel, $N F-k B 1$ and NF- $k B 2$ ) of the NF- $k B$ transcription factor family. $N F-k B$ members can potentially generate fifteen NF- $k B$ homoor heterodimers which will bind to $k B$ sequence elements present in the promoter or enhancer regions of target genes, regulating multiple pathways involved in cell survival and death, organ development, inflammation and immunological responses. ${ }^{3}$ All NF-KB members share a Rel homology domain responsible for DNA-binding and dimerisation however, only three of them (RelA, RelB, c-Rel) have a C-terminal transactivation domain which is required to modulate gene transcription. NF-kB1 ( 550 , generated from the precursor $\mathrm{p} 105)$ and NF-KB2 (p52, generated from the precursor $p 100)$ lack this domain and acquire transactivation function by either forming Rel/p50 and Rel/p52 heterodimers or associating with non-Rel coactivator proteins. ${ }^{4,5} \mathrm{NF}-\kappa \mathrm{B} 1$ (p50) and 2 (p52) proteins can also form homodimers which have an important role as transcriptional repressors, modifying expression of NF- $k B$ target genes, including those involved in inflammation. ${ }^{6,7}$

Increasing evidence suggests important roles for NF- $\mathrm{kB}$ proteins in renal disease progression, ${ }^{8}$ mediating renal inflammation by promoting gene expression in different cell types, including renal cells, innate immune cells and lymphocytes. ${ }^{9}$ Many reports regarding NF- $k B$ function in vivo focus on RelA/p50 heterodimers, overlooking the complexity of this transcription factor family. Due to the potential dual role of the NF-kB1 in both promoting and repressing inflammation further studies are needed in order to clarify the role of this subunit in renal disease pathophysiology.

To characterise the contribution of NF-kB1 in the development of immune complex driven kidney disease we used the nephrotoxic serum (NTS) glomerulonephritis model. In this manuscript we report that animals deficient in NF-kB1 (p50 and its precursor $\mathrm{p} 105$ ) had more severe glomerular injury and

\footnotetext{
${ }^{1}$ Institute of Cellular Medicine, Newcastle University, Newcastle Upon Tyne, UK; ${ }^{2}$ Urology Department, Cipto Mangunkusumo National Referral Hospital/Faculty of Medicine, Universitas Indonesia, Jakarta, Indonesia and ${ }^{3} \mathrm{MRC}$ Transplant Centre, Kings College London, London, UK

${ }^{*}$ Corresponding author: N Sheerin, Institute of Cellular Medicine. William Leech Building. Newcastle University, 4th Floor Leech Building, Medical School, Framlington Place, William Leech Building, Newcastle Upon Tyne NE24HH, UK. Tel: +44 191 2087146; Fax: +44 191208 7770; E-mail: neil.sheerin@ ncl.ac.uk

${ }^{4}$ These authors contributed equally to this work.

Received 09.1.17; revised 29.3.17; accepted 19.4.17; Edited by T Brunner
} 
a persistent inflammatory response following NTS injection. A shared contribution to this phenotype by both bone marrowderived inflammatory cells and resident renal cells was demonstrated using bone marrow chimeric mice. However, in contrast to acute inflammatory injury, absence of NF-kB1 did not alter the progression of chronic injury. Therefore NF- $k \mathrm{~B} 1$ has an important role driving the early inflammatory response in infiltrating and resident renal cells during the acute phase of glomerulonephritis.

\section{Results}

NF-kB1 deficiency exacerbates glomerular injury in NTS nephritis. The NTS nephritis mouse model has many features which are common to clinical GN. These include, inflammatory cell influx to the kidney, proteinuria, and crescentic glomerulonephritis. In this model proteinuria and transient kidney injury is achieved by the administration of sheep anti-mouse glomerular basement membrane (GBM) heterologous antibodies which bind to target antigens in the recipient glomerulus. WT and $n f k b 1^{-1-}$ mice were given NTS through tail vein injection and kidneys harvested after 2 or $24 \mathrm{~h}$. Neutrophil infiltration was evident $2 \mathrm{~h}$ after NTS injection. No differences in the number of infiltrating neutrophils (Figure 1a; Supplementary Figures $1 \mathrm{~A}$ and $\mathrm{B}$ ) or macrophages (Figure 1b; Supplementary Figure 1C) per glomerulus were detected between WT and $\mathrm{n} f \mathrm{k} b 1^{-1-}$ mice. Of note and consistent with previous reports in this model, $24 \mathrm{~h}$ after NTS injection the neutrophil infiltrate had resolved (Figure 1a).

Glomerular injury and thrombosis was evident in WT and $n \mathrm{n}_{\mathrm{K}} b 1^{-l-}$ mice after $24 \mathrm{~h}$ of NTS injection. Glomerular injury was significantly worse in $n f k b 1^{-1-}$ mice compared with WT mice. Extensive glomerular thrombosis was only evident in $n f_{k} b 1^{-1-}$ animals (Figure 1c). Therefore, lack of NF-kB1 results in worse and more extensive glomerular injury during NTS-induced GN.

Proteinuria is increased in mice deficient in NF-кB1 despite equivalent binding of heterologous antibody. To confirm that the excess glomerular injury observed in the $n f k b 1^{-1-}$ mice (Figure 1c) was not due to a difference in nephrotoxic antibody binding, the amount of sheep IgG present in the glomeruli was quantified at 2 and $24 \mathrm{~h}$ postinjection. No significant differences of the mean fluorescence intensity was detected in the glomeruli of WT and $n f k b 1^{-\prime-}$ mice at 2 or $24 \mathrm{~h}$ indicating no differential binding of the antiGBM heterologous antibody (Figure 2a). Complement activation, as assessed by $\mathrm{C} 3$ deposition in the glomeruli, was also similar in WT and $n f k b 1^{-l-}$ mice $2 \mathrm{~h}$ after NTS injection (Figure 2b).

In addition to histological glomerular injury, glomerular function was assessed by measuring $24 \mathrm{~h}$ urine albumin excretion. NTS injection resulted in functional injury to the glomerulus as reflected by an increase in urine albumin excretion in WT and $n f_{k} b 1^{-1-}$ mice after NTS challenge (Figure 2c). The $n f k b 1^{-1-}$ mice exhibited significantly higher urinary albumin excretion than WT.
To determine whether $n f k b 1^{-1-}$ mice had an increased sustained response to injury over time, disease severity was assessed 7 days after NTS administration. Blood urea nitrogen analysis showed no differences in kidney function between WT and $n f_{k} b 1^{-1-}$ mice (Supplementary Figure 2A). In addition no differences were detected in the glomerular injury score (Supplementary Figure 2B) and macrophage infiltration (Supplementary Figure 2C) in the glomeruli of WT and $n f k b 1^{-/-}$mice. Taken together with the histological changes this result confirms that NF- $k \mathrm{~B} 1$ is important in preserving glomerular structure and function during acute experimental GN.

NF-KB1 deficiency increases pro-inflammatory gene expression. Disease progression on the NTS-induced nephritis model can be divided in two distinctive phases. During the first few days (or the 'heterologous' phase) the damage is dependent upon infiltrating neutrophils, complement activation and pro-inflammatory cytokines. ${ }^{10}$

To assess the inflammatory response of both WT and $n \mathrm{k}_{\mathrm{k}} b 1^{-1-}$ mice we determined the levels of key proinflammatory proteins (TNF-a, IL-6, S100A8 and S100A9) which are known downstream targets for NF- $\kappa \mathrm{B}$ as well as recognised contributors to GN disease progression. ${ }^{11-13}$ TNFa, S100A8 and S100A9 gene expression in kidney was upregulated $2 \mathrm{~h}$ after NTS challenge in both WT and $n f_{k} b 1^{-/-}$ (Figures 3a,c,d) in comparison with WT saline injected animals. No difference was seen in IL-6 expression (Figure 3b). TNF-a levels were significantly higher in $n f K b 1^{-1-}$ versus WT mice $2 \mathrm{~h}$ after NTS injection (Figure 3a). Although the levels of TNF- $a$, S100A8 and S100A9 expression in $n f k b 1^{-1-}$ mice had fallen by $24 \mathrm{~h}$, they were significantly higher than in the WT group (Figures 3a,c,d). These data are consistent with NF-kB being involved in both onset and resolution of acute inflammation. ${ }^{14}$

NF-кB1 in both immune and resident renal cells is involved in the development of injury. NF-kB activation can have a dual role driving renal disease by regulating immune cell biological responses as well as modulating the response of resident renal cells to injury. ${ }^{8}$ To dissect the contribution of $\mathrm{Nf}_{\kappa} \mathrm{b} 1$ to disease development in immune and resident cells we generated bone marrow chimeric animals. Recipient mice were irradiated and transplanted with bone marrow hematopoietic progenitor cells from donor mice generating four chimeric combination: WT to WT, $n f_{k} b 1^{-1-}$ to $n f_{k} b 1^{-1-}, n f_{k} b 1^{-1-}$ to WT, WT to $n f k b 1^{-1-}$. Peripheral blood screening confirmed bone marrow conversion to donortype after 6 weeks (Supplementary Figures 3A and B). NTS nephritis was induced in the four chimeric groups by NTS injection. Binding of antibody to the GBM was the same across the different chimeric mice (Supplementary Figure 4). In agreement with Figures $1 \mathrm{c}$ and d, glomerular injury score was significantly higher in $n f_{k} b 1^{-I_{-}} \rightarrow n f k b 1^{-1-}$, than in control chimeric WT $\rightarrow$ WT mice. Mice deficient in NF- $k$ B1 in either bone marrow-derived cells $\left(n f k b 1^{-1-} \rightarrow \mathrm{WT}\right)$ or renal resident cells $\left(\mathrm{WT} \rightarrow n \mathrm{~K}_{\mathrm{K}} b 1^{-/-}\right)$developed significantly greater glomerular injury compared with control chimeric $\mathrm{WT} \rightarrow \mathrm{WT}$ (Figure $4 \mathrm{a}$ ). This result suggests a role for NF- $k \mathrm{~B} 1$ in both bone marrow-derived cells and renal resident cells 
a
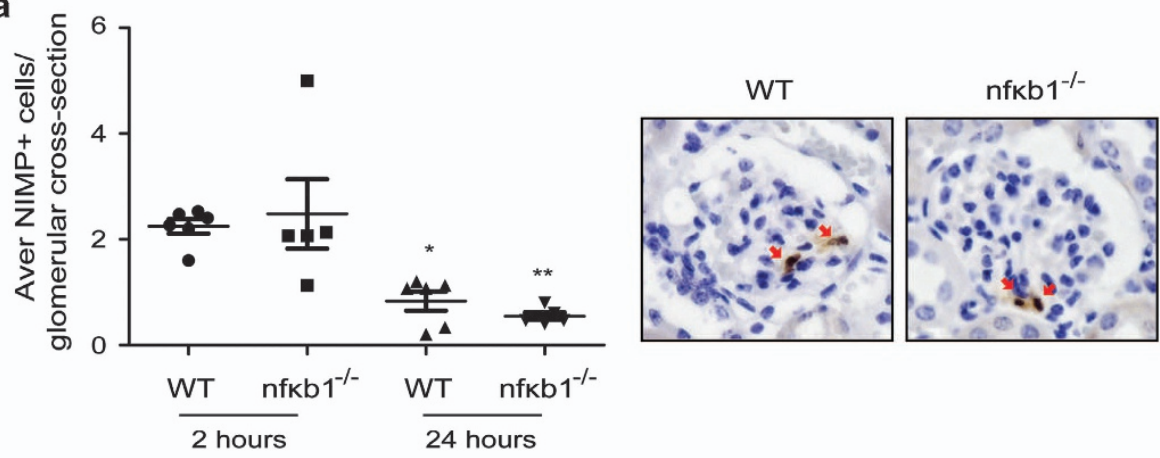

b
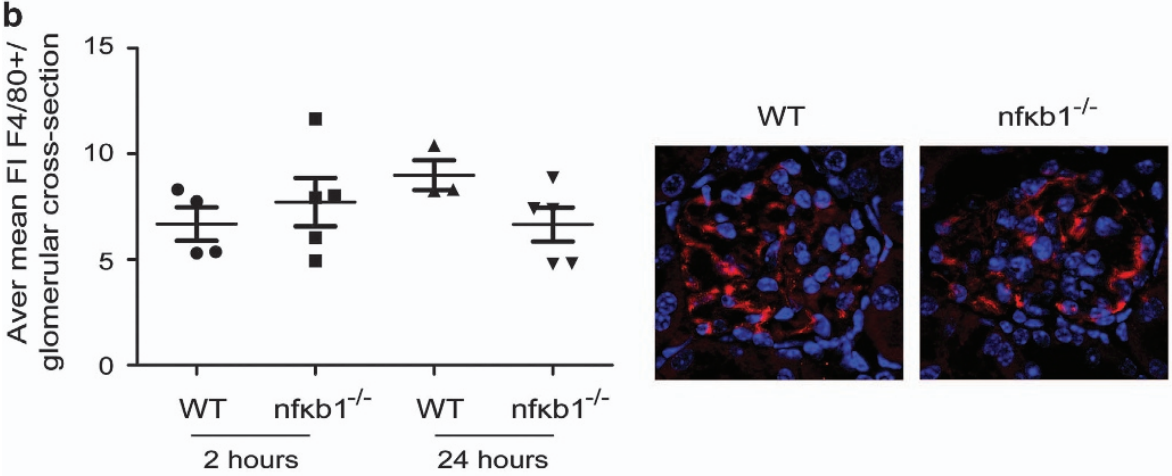

c
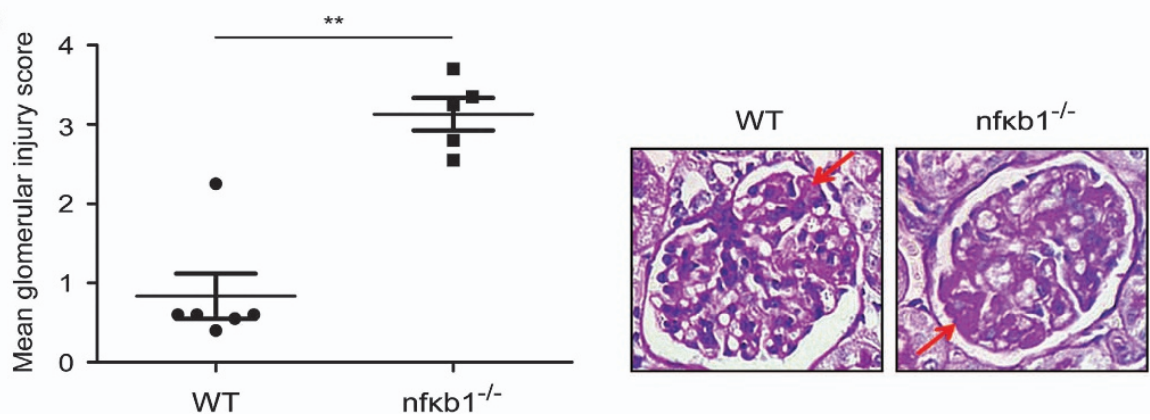

Figure 1 NF- $\kappa$ B1-deficient mice have more severe glomerular injury after NTS-induced glomerulonephritis. Average number of neutrophils (NIMP+) per glomerular crosssection in WT and $n f \kappa b 1^{-1-}$ renal tissues 2 and $24 \mathrm{~h}$ post-NTS injection and representative NIMP IHP pictures at $2 \mathrm{~h}$ showing neutrophil infiltration (red arrows) in a glomeruli (a). Average mean fluorescence intensity of F4/80+ staining per glomerular cross-section in WT and $n f k b 1^{-1}$ renal tissues 2 and $24 \mathrm{~h}$ post-NTS injection and representative F4/80 IHP pictures at $24 \mathrm{~h}$ showing macrophage positive staining in a glomeruli (b). Glomerular injury score in WTand $n f k b 1^{-1-}$ mice $24 \mathrm{~h}$ post-NTS injection and representative PAS pictures showing areas of glomerular thrombosis (red arrows) in a glomeruli (c). $N=6$, unpaired $t$-test, ${ }^{\star} P \leqslant 0.05$ or ${ }^{\star \star} P \leqslant 0.01$

during the development of glomerular injury following NTS injection.

Glomerular function was assessed in chimeric mice by analysing $24 \mathrm{~h}$ urine albumin excretion. The level of albuminuria was higher in $n f_{k} b 1^{-l-} \rightarrow n f_{k} b 1^{-1-}$ than in WT $\rightarrow$ WT (Figure 4b) consistent with worse glomerular function. Transplant of $n f k b 1^{-1-}$ bone marrow into WT mice $\left(n f_{k} b 1^{-1-} \rightarrow \mathrm{WT}\right)$ or WT bone marrow into $n f k b 1^{-1-}(\mathrm{WT} \rightarrow$ $n f_{k} b 1^{-1-}$ ) led to similar levels of albuminuria as $n f_{k} b 1^{-1-}$ $\rightarrow n f k b 1^{-1-}$. Therefore glomerular permselectivity is also dependent on the absence of NF- $k \mathrm{~B} 1$ in bone marrowderived cells and renal resident cells.

Absence of NF-кB1 in either immune or resident renal cells leads to slower resolution of the acute inflammatory response to NTS-induced nephritis. Resolution of the inflammatory response to NTS injection was delayed in mice deficient in NF-kB1 (Figures 3a-d) which could contribute to the greater glomerular injury (Figure 1c) and impaired glomerular function (Figure 2c) present in these animals. We next analysed the contribution from infiltrating inflammatory cells and resident renal cells to this delayed resolution phenotype. Gene expression levels of TNF-a, IL-6, S100A8 and S100A9 were analysed in the four different chimeric mice $24 \mathrm{~h}$ after NTS injection. As expected $n f_{k} b 1^{-I-} \rightarrow n f_{k} b 1^{-I-}$ mice showed higher levels of TNF- $a$, IL-6, S100A8 and S100A9 than WT $\rightarrow$ WT (Figures $5 a-d$ ). Lack of NF-kB1 in both bone marrow-derived immune cells $\left(n f_{k} b 1^{-l-} \rightarrow\right.$ WT) and kidney resident cells (WT $\rightarrow n f_{k} b 1^{-1-}$ ) was associated with higher levels of TNF- $a$ in comparison to chimeric WT $\rightarrow$ WT (Figure 5a). Transplant of $n f k b 1^{-1-}$ bone marrow into WT $\left(n f_{k} b 1^{-l-} \rightarrow \mathrm{WT}\right)$ resulted in expression of IL-6, S100A8 and S100A9 (Figures 5b-d) close to WT $\rightarrow$ WT levels. WT bone marrow transplant into $n f k b 1^{-1-}$ showed an 

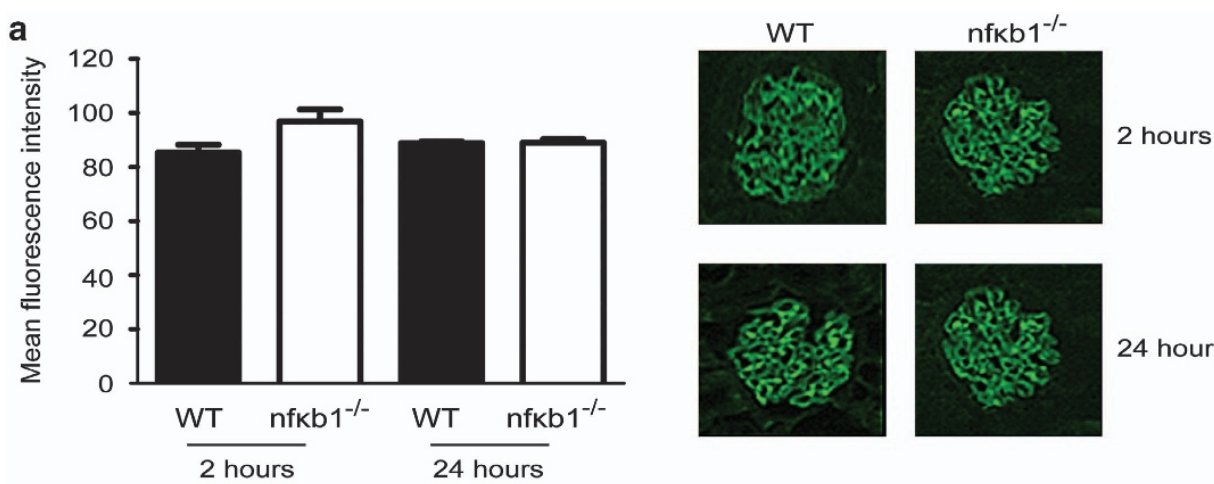

24 hours

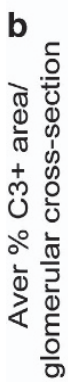
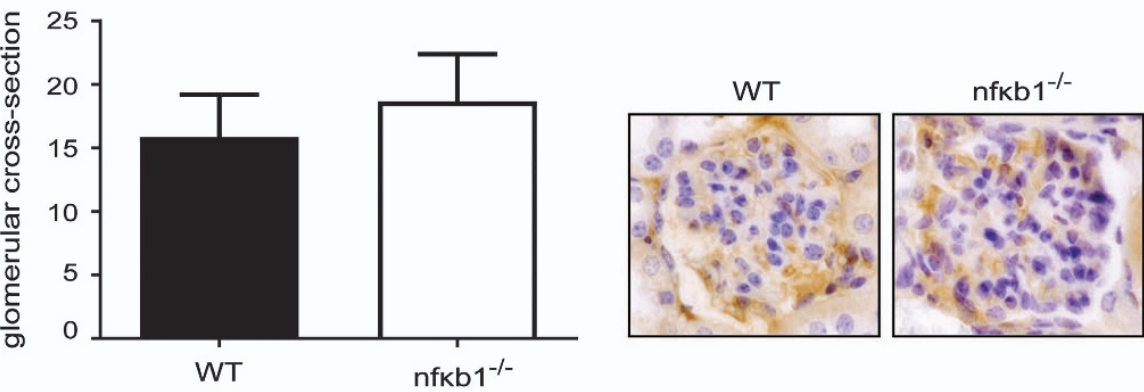

c

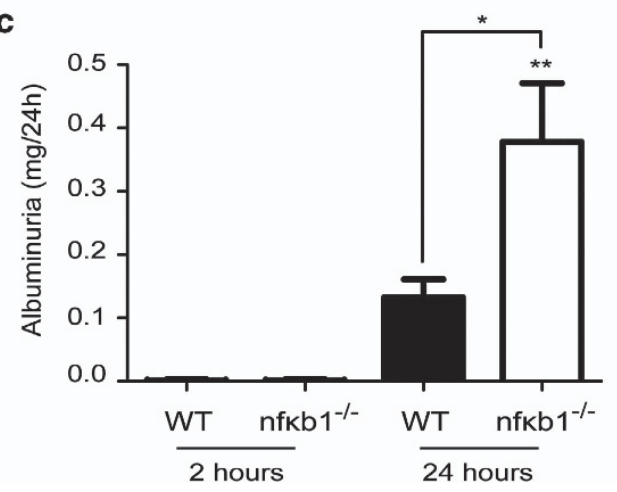

Figure 2 NF-кB1-deficient mice have impaired glomerular function after NTS-induced glomerulonephritis despite equivalent heterologous antibody deposition. Mean fluorescence intensity quantification and representative pictures (a) of anti-GMB antibody binding to glomerular basal membrane of the glomeruli 2 and $24 \mathrm{~h}$ post-NTS injection in WT and $n f k b 1^{-1-}$ mice. Average of \% C3+ area per glomerular cross-section in WT and $\mathrm{nf} \kappa b 1^{-1-}$ renal tissues $2 \mathrm{~h}$ post-NTS injection and representative pictures showing C3 positive staining in a glomeruli (b). Albumin concentration in the urine collected for $24 \mathrm{~h}$ after 2 or $24 \mathrm{~h} \mathrm{NTS}$ injection (c). $N=6$, one way ANOVA, ${ }^{*} P \leqslant 0.05$ or ${ }^{* *} P \leqslant 0.01$

intermediate phenotype between $n f_{k} b 1^{-1-} \rightarrow n f k b 1^{-1-}$ and WT $\rightarrow$ WT. Of note, IL-6 gene expression in non-chimeric (Figure $3 b$ ) and chimeric mice (Figure 5b) after NTS challenge was different. This could be down to the presence of resident monocytic cells in the chimeric mice, which will not be affected by the chimeric switch and could influence tissue inflammation.

These results indicate that NF- $k \mathrm{~B} 1$ is responsible for gene and cell regulation and that both circulating immune cells and renal resident cells contribute to the delayed resolution response present in the $n f k b 1^{-1-}$ mice.

Increased inflammatory responses in circulating and resident renal cells deficient in NF-кB1. We next explored the role of NF- $\kappa \mathrm{B} 1$ in circulating and resident renal cells. To assess the contribution of circulating cells we focused on bone marrow-derived macrophages and circulating leukocytes which are important effectors of the heterologous phase of NTS-induced nephritis. Circulating leukocytes from WT and $n f_{k} b 1^{-1-}$ were exposed to different inflammatory stimuli. $N f_{k} b 1^{-1}$ - leukocytes had a greater oxidative response to Escherichia coli, but not fMLP or PMA, compared with WT (Figures $6 \mathrm{a}$ and $\mathrm{b}$ ). In agreement with the gene expression levels of the NTS-challenged chimeric mice (Figures $5 a-d$ ), $n f_{k} b 1^{-1-}$ bone marrow-derived macrophages stimulated with LPS showed greater and sustained levels of TNF- $a$ gene expression (Figure 6c) compared with WT macrophages but similar levels of S1A008 (Figure 6d).

Mesangial cells have an important role in glomerular inflammation. ${ }^{15}$ Mesangial cells were isolated from WT and $n \mathrm{~K}_{\mathrm{K}} b 1^{-1-}$ mice, treated with LPS for 2 and $24 \mathrm{~h}$ and gene expression for TNF- $a$ and S100A8 was evaluated. While WT 

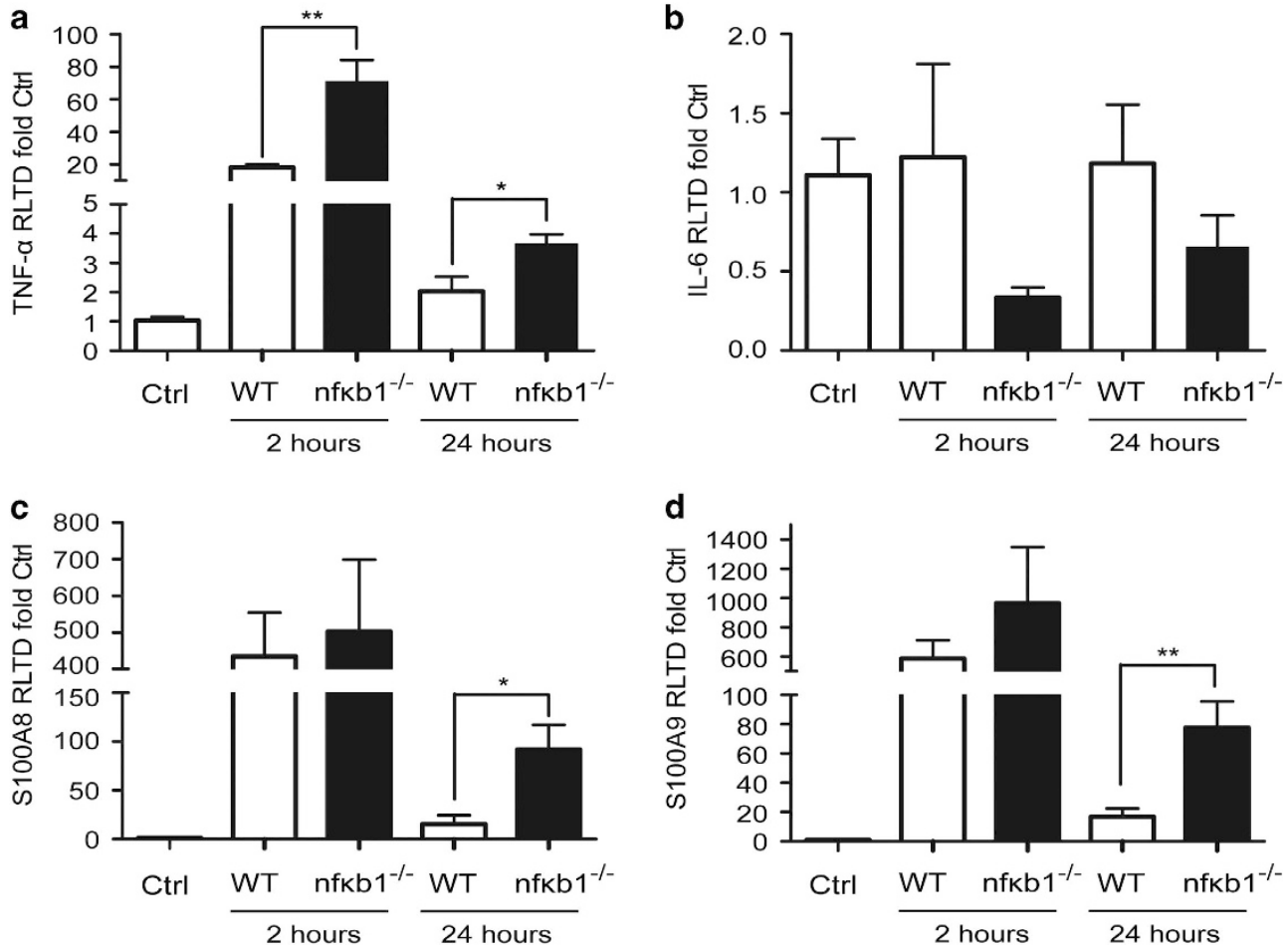

Figure 3 NF-kB1-deficient mice have increased and sustained inflammatory responses after NTS-induced glomerulonephritis. TNF- $\alpha$ (a), IL-6 (b), S100A8 (c) and S100A9 (d) mRNA expression in kidney from saline and NTS-challenged WT and nfkb $1^{-1-}$ mice at 2 and $24 \mathrm{~h} . N=6$, repeated series of $t$-test, ${ }^{\star} P \leqslant 0.05$ or ${ }^{\star *} P \leqslant 0.01$
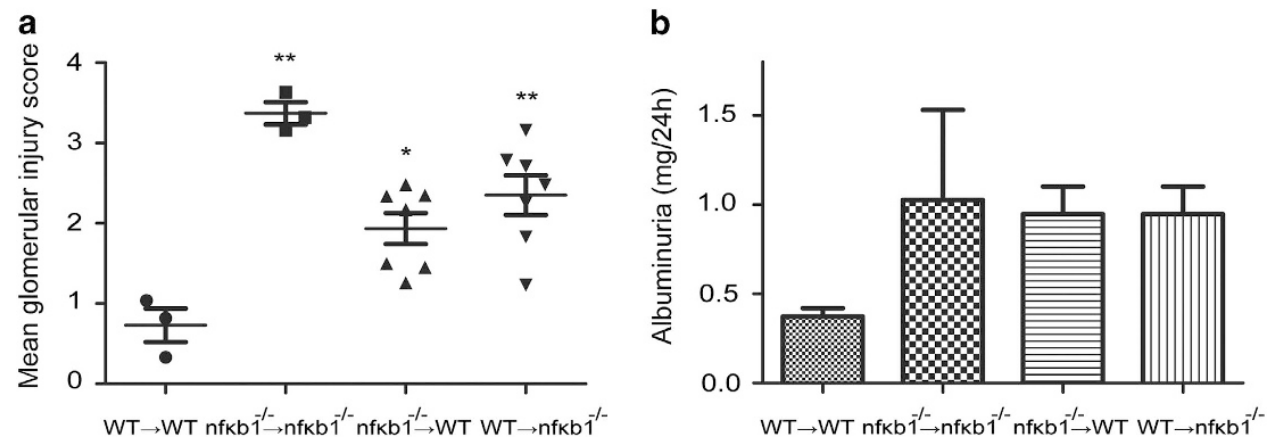

Figure 4 Glomerular injury is driven by the lack of NF-kB1 in circulating and renal resident cells after NTS-induced glomerulonephritis. Glomerular injury score in chimeric mice WT $\rightarrow W T, n f \kappa b 1^{-1-} \rightarrow n f \kappa b 1^{-1-}, n f \kappa b 1^{-1-} \rightarrow W T$ and WT $\rightarrow n f \kappa b 1^{-1-}$ (a). Albumin concentration in the urine collected for $24 \mathrm{~h}$ after $24 \mathrm{~h} \mathrm{NTS}$ injection (b). N $=7$ for $n f_{\kappa} b 1^{-1-} \rightarrow$ WT and WT $\rightarrow n f \kappa b 1^{-1-}$, one way ANOVA, ${ }^{*} P \leqslant 0.05$ or ${ }^{* *} P \leqslant 0.01$

mesangial cells were almost unresponsive to LPS, $n f_{k} b 1^{-1-}$ mesangial cells demonstrated a significant response at 2 and $24 \mathrm{~h}$ (Figures $7 \mathrm{a}-\mathrm{d}$ ). Our results confirm circulating and renal mesangial cells deficient in NF- $\kappa \mathrm{B} 1$ generate a greater inflammatory response than WT cells, pointing towards an anti-inflammatory role for NF- $\mathrm{kB} 1$.

NF- $\mathrm{BB} 1$ bone marrow-derived macrophages present an impaired MAPK phosphorylation response to TNF-a. NF- $k$ B1 has been implicated in the regulation of MAPK signalling pathway ${ }^{16,17}$ which also have an important role regulating the immune response. Therefore, we next investigated the activation of MAPK in WT and $n f_{k} b 1^{-1-}$ bone marrow-derived macrophages stimulated with TNF-a. $N f_{K} b 1^{-I-}$ bone marrow-derived macrophages showed lower levels of P38 and ERK phosphorylation after TNF-a treatment
(Figure 7e). In agreement, JNK phosphorylation was also lower in $n f k b 1^{-1-}$ bone marrow-derived macrophages than in WT. Of note, a second phosphorylation wave of P38 and ERK was observed $2 \mathrm{~h}$ after TNF- $a$ stimulation in WT cells. This was absent in $n f k b 1^{-1-}$ bone marrow-derived macrophages (Figure 7e). Our results demonstrate a defective MAPK phosphorylation response in $n f_{k} b 1^{-/-}$macrophages.

NF- $\kappa$ B1 deficiency does not increase the severity of injury after UUO. Our results had clearly demonstrated NF- $k$ B1 deficiency worsens acute glomerular pathology, we next assessed whether it had a similar effect on the more chronic injury associated with ureteric obstruction. To study the inflammatory and the fibrotic phase of this model we performed unilateral ureteric obstruction (UUO) in WT and $n f k b 1^{-1-}$ mice and harvested the kidneys at 3 and 10 days. 

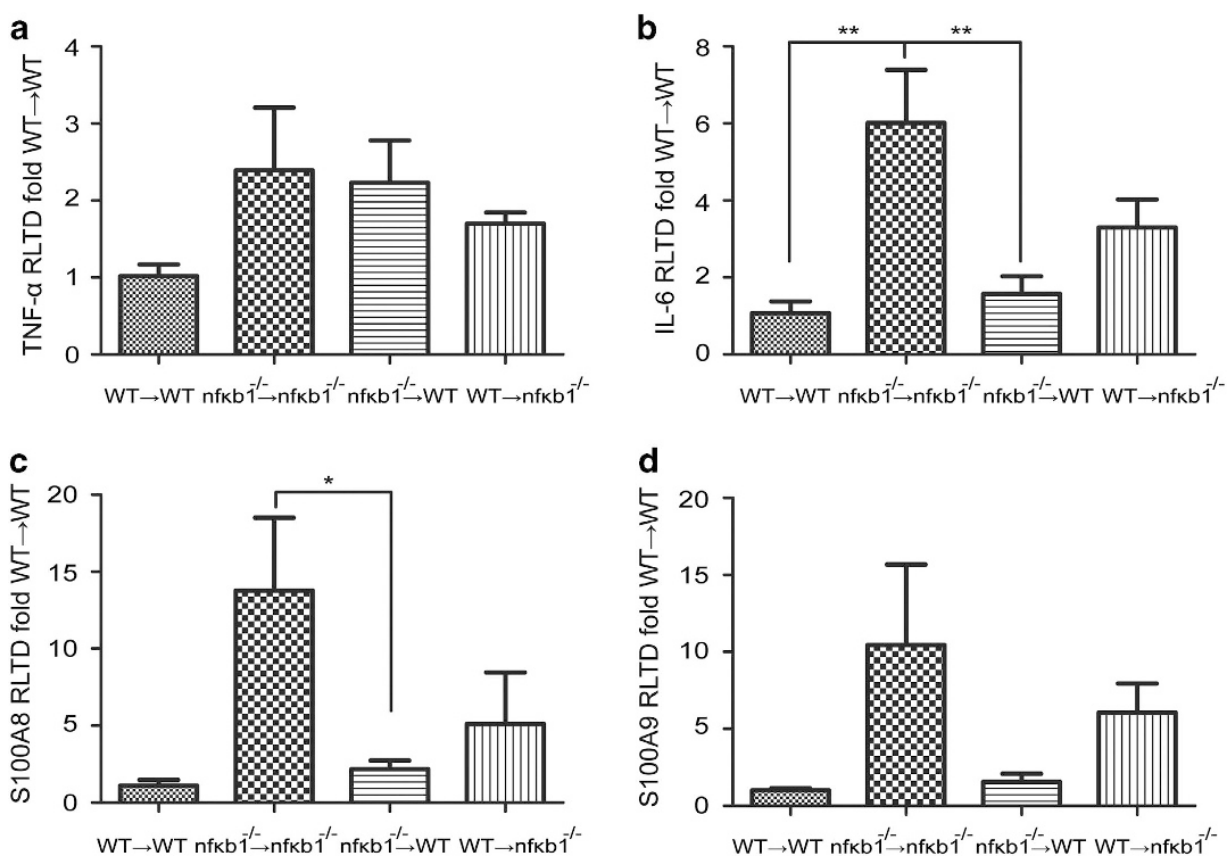

Figure 5 NF- $k B 1$ deficiency in both circulating and resident kidney cells regulates cytokine gene expression. TNF- $\alpha$ (a), IL-6 (b), S100A8 (c) and S100A9 (d) mRNA

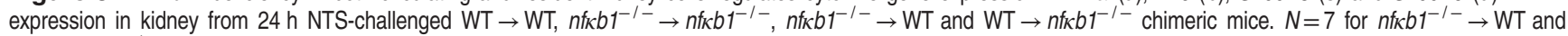
WT $\rightarrow n f \kappa b 1^{-l-}$, one way ANOVA, ${ }^{*} P \leqslant 0.05$ or ${ }^{* \star} P \leqslant 0.01$

Tubular dilatation and interstitial expansion (Figures $8 a$ and b) was significantly higher during the inflammatory phase of the model ( 3 days post-UUO) in $n f k b 1^{-1-}$ mice versus WT. However, 10 days after UUO tubular dilatation and interstitial expansion were equivalent in WT and $n f k b 1^{-1-}$ mice (Figures $8 \mathrm{c}$ and d). Our results demonstrate that NF-KB1 is important in the early phases of glomerular and tubular injury but deficiency does not influence the progression into the chronic/fibrotic phase.

\section{Discussion}

The clinical manifestations of glomerulonephritis (GN) are a result of acute often persistent inflammation. Research into the immune and inflammatory basis of glomerulonephritis tend to focus on the mechanisms that drive glomerular inflammation. However, there may be pathways that regulate inflammation and therefore influence the severity of injury. In this manuscript we describe a key role for NF-kB1, expressed in both resident and infiltrating cells, in the regulation of glomerular inflammation.

$\mathrm{NF}-\mathrm{KB}$ is a family of pleiotropic transcription factors regulating transcription of hundreds of genes related to inflammation, immunity, apoptosis, cell proliferation and differentiation. NF- $\kappa B$ is known to be activated in both patients with kidney disease (diabetic nephropathy, ${ }^{18}$ glomerular disease ${ }^{19}$ ) and animal models of renal inflammation and injury. ${ }^{8} \mathrm{NF}-\mathrm{KB}$ is considered to promote inflammation during renal disease with evidence correlating NF- $k B$ activation to the severity of renal disease. ${ }^{18,20}$ However, most of the reports are limited to the function of the NF-kB heterodimer, RelA/p50, while the function of other NF- $k B$ complexes in renal disease is still not clear. It has been suggested that the NF-kB1 subunit, $\mathrm{p} 50$, which is encoded by $n f-k b 1$ gene, has a dual role in many pathological processes promoting inflammation as heterodimer (RelA/p50) or repressing it as homodimer (p50/p50). ${ }^{21}$

Here we investigate the role of NF- $k$ B1 in NTS-induced GN mouse model. Our results demonstrate $n f k b 1^{-1-}$ mice, which are deficient in p50 subunit and its precursor p105, had increased glomerular injury (Figures $1 \mathrm{c}$ and 2c) $24 \mathrm{~h}$ after NTS injection compared with WT mice. Similar levels of infiltrating neutrophils (Figure 1a; Supplementary Figures 1A,B), macrophages (Figure 1b; Supplementary Figure 1C) and C3 deposition (Figure $2 b$ ) were seen at the site of injury suggesting an equivalent immediate response to heterologous antibody, in WT and $n f k b 1^{-1-}$ mice but the subsequent injury that developed at $24 \mathrm{~h}$ was more severe. Our results are consistent with the proposed protective role of p50 in rat models of ischaemia reperfusion ${ }^{22}$ and anti-Thy 1 glomerulonephritis. ${ }^{23}$ Prolonged NTS challenge (7 days) did not demonstrate delayed injury resolution in $n f k b 1^{-1-}$ mice (Supplementary Figures $2 \mathrm{~A}-\mathrm{C}$ ), demonstrating an important function for NF-KB1 during acute but not chronic experimental GN.

$\mathrm{NF}-\mathrm{kB}$ is involved in both the initiation and resolution of the acute inflammatory response ${ }^{14}$ having opposite roles at different stages of inflammation. During the initiation NF-kB stimulates the synthesis of inflammatory mediators such as TNF- $a$, angiotensin II and monocyte chemoattractant protein-1 (MCP-1). In contrast during resolution, NF-kB down-regulates inflammatory genes, up-regulates anti-inflammatory genes and induces apoptosis of leukocytes. Our assessment of inflammatory mediators in WT and $n f k b 1^{-1-}$ mice after 2 and $24 \mathrm{~h}$ of NTS challenge demonstrated an 

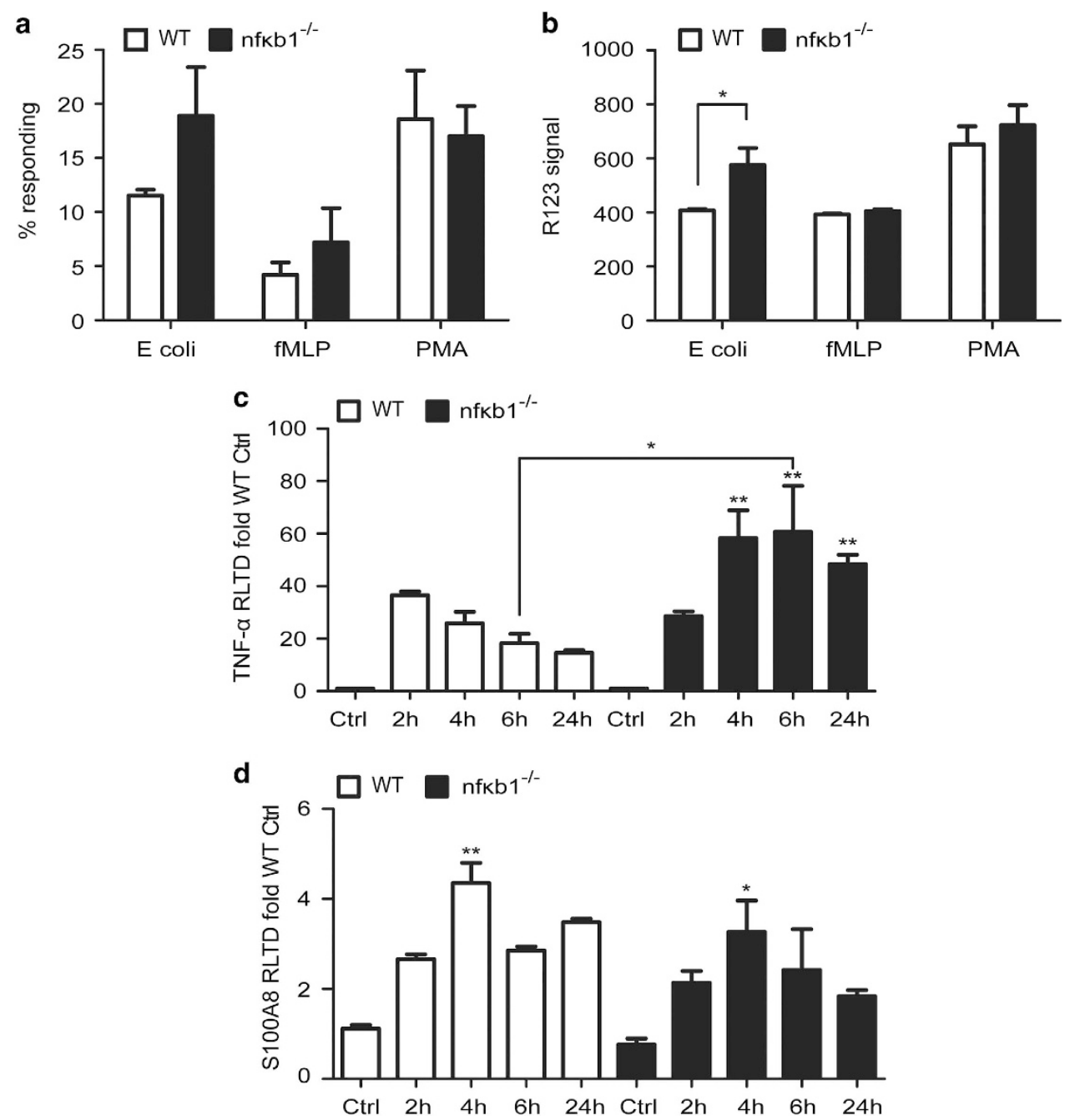

Figure 6 Inflammatory responses from WT and NF-kB1-deficient leukocytes and macrophages. Percentage of WT or nfkb1 ${ }^{-1-}$ circulating leukocytes producing reactive oxidants (conversion of DHR123 to R123) after stimulation with E. coli, fMLP and PMA (a). Enzymatic activity per cell as expressed by R123 signal in circulating leukocytes of WT or $n f k b 1^{-1-}$ after stimulation with E. coli, fMLP and PMA (b). TNF- $\alpha$ (c) and S100A8 (d) mRNA expression in bone marrow-derived macrophages from WT or $n f k b 1^{-1-}$ treated with $100 \mathrm{ng} / \mathrm{ml}$ of LPS for $2,4,6$ and 24 h. $N=3$, unpaired $t$-test $(\mathbf{a}, \mathbf{b})$, one way ANOVA $(\mathbf{c}, \mathbf{d}),{ }^{*} P \leqslant 0.05$ or ${ }^{* *} P \leqslant 0.01$

increased and sustained inflammatory response (Figures $3 a-d)$ in $n f k b 1^{-1-}$ mice. The more severe phenotype observed in the $n \mathrm{~K}_{\mathrm{K}} \mathrm{b} 1^{-1-}$ mice could be a result of the absence of p50/p50 homodimers, which are thought to act as repressors for the NF- $\kappa \mathrm{B}$ mediated inflammatory gene induction during experimental renal injury. ${ }^{22}$

During renal disease NF- $k \mathrm{~B}$ controls injury by modulating the response of infiltrating immune cells and kidney resident cells. To analyse the contribution of each of these cell types we generated bone marrow chimeras. WT mice receiving WT bone marrow had the least severe disease. The absence of NF-kB1 in either infiltrating bone marrow-derived cells or resident renal cells resulted in an increase in disease severity (Figures $4 \mathrm{a}$ and $\mathrm{b}$ ). This is consistent with the hypothesis that NF-kB1 has regulatory functions in both resident and infiltrating cells.

Evidence for the regulatory function of NF-kB1 in both resident and infiltrating cells was obtained using isolated bone marrow-derived macrophages and renal mesangial cells.
Macrophages from $n f k b 1^{-1-}$ mice had greater TNF-a expression compared with WT macrophages after LPS challenge (Figure 6c), whilst mesangial cells had increased expression of both TNF- $a$ and S100A8 (Figures $7 a-d$ ). With the recent report of a key role for the proteins S100A8 and S100A ${ }^{13}$ in glomerular inflammation and the known function of TNF- $a$, NF-kB1 may regulate multiple pathways involved in glomerular inflammation.

To have its essential role controlling inflammation, NF-kB requires the assistance of other transcription factors, such as members of the activator protein (AP)-1 family, which are dependent on mitogen activated protein kinase (MAPK) signalling pathways. ${ }^{24}$ Therefore we next analysed the MAPK signalling pathways in bone marrow-derived macrophages after TNF- $a$ treatment. In agreement with previous reports, ${ }^{16,25} \mathrm{~N}_{\mathrm{K}} b 1^{-1-}$ bone marrow-derived macrophages showed impaired MAPK phosphorylation in comparison with WT (Figure 7e). NF-kB1 can regulate TPL-2 activity, which is the upstream kinase for the activation of the MAPKs. ${ }^{26}$ Further 

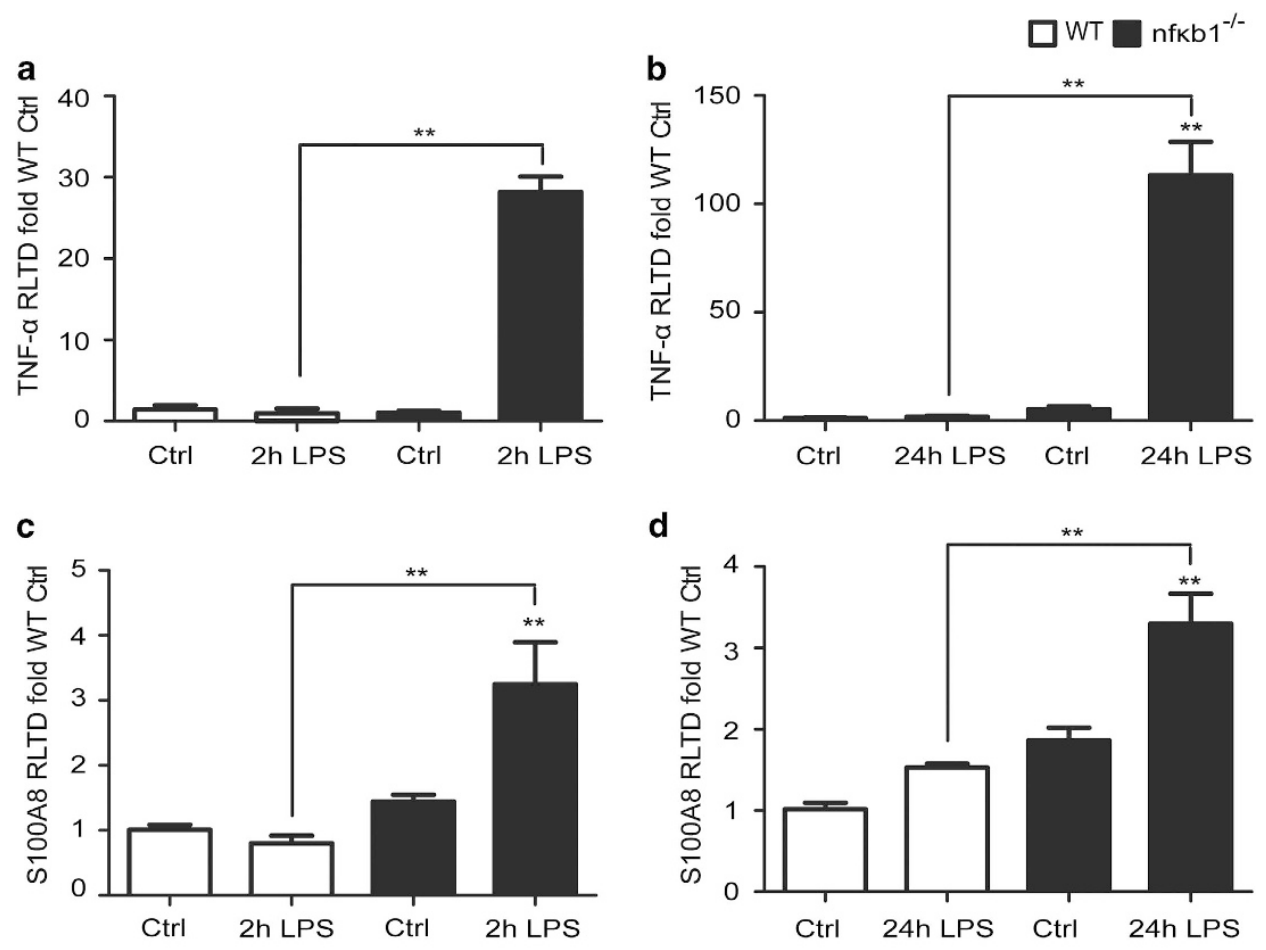

d
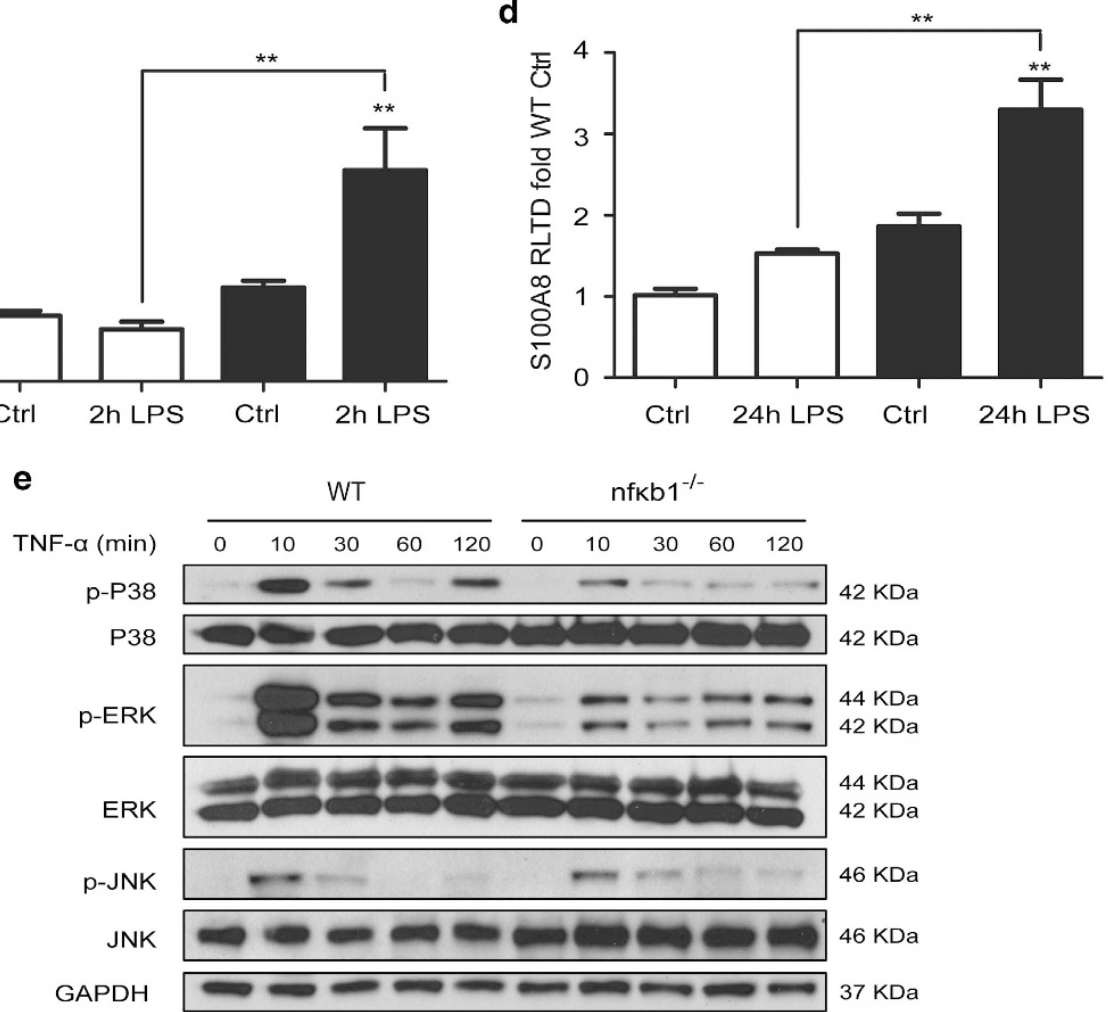

Figure 7 Renal resident mesanglial cells and bone marrow-derived macrophages deficient in NF- $k$ B1 present increased inflammatory responses and impaired MAPK

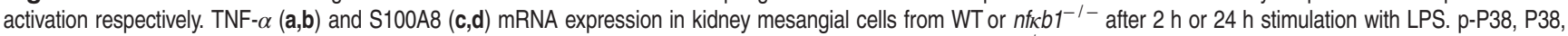
p-ERK, ERK, p-JNK, JNK and GAPDH protein expression in bone marrow-derived macrophages from WTor $n f \kappa b 1^{-1-}$ treated with $50 \mathrm{ng} / \mathrm{ml}$ of TNF- $\alpha$ for $10,30,60$ and $120 \mathrm{~min}$ (e). $N=3$, one way ANOVA, ${ }^{*} P \leqslant 0.05$ or ${ }^{* *} P \leqslant 0.01$

investigation will need to be done to fully understand the relative contribution of altered NF-kB function and the impaired activation of the MAPKs to the altered immune responses present in the $n f k b 1^{-1-}$ mice.

In addition to the phenotype in bone marrow-derived macrophages and renal mesangial cells, isolated leukocytes from $n f k b 1^{-1-}$ mice showed greater oxidative response than WT (Figures $6 \mathrm{a}$ and b), therefore infiltration of $n f k b 1^{-1-}$ leukocytes in the site of injury have the potential to cause greater damage. As reported previously our data suggests that NF-kB1 controls cell responses in multiple cell types.

Previous reports have also described not only a cell dependent but also a time-dependent role for NF-kB1 during acute renal injury. Absence of NF-kB1 during the first $24 \mathrm{~h}$ of sepsis-induced acute kidney injury reduced renal inflammation, ${ }^{27}$ however the lack of NF-kB1 at $48 \mathrm{~h}$ resulted in higher mortality and prolonged renal inflammation. ${ }^{23}$ To analyse the role of p50 in a more chronic injury we used the tubular injury model of unilateral ureteric obstruction or UUO. NF-kB1 absence led to increased tubular dilatation and interstitial expansion after UUO during the inflammatory phase of the injury, 3 days (Figures $8 \mathrm{a}$ and b). However, no differences where observed in the chronic/fibrotic phase, 10 days (Figures $8 \mathrm{c}$ and d). Our results demonstrate a critical protective role for NF-kB1 during the onset of acute renal injury but not the chronic phase. 

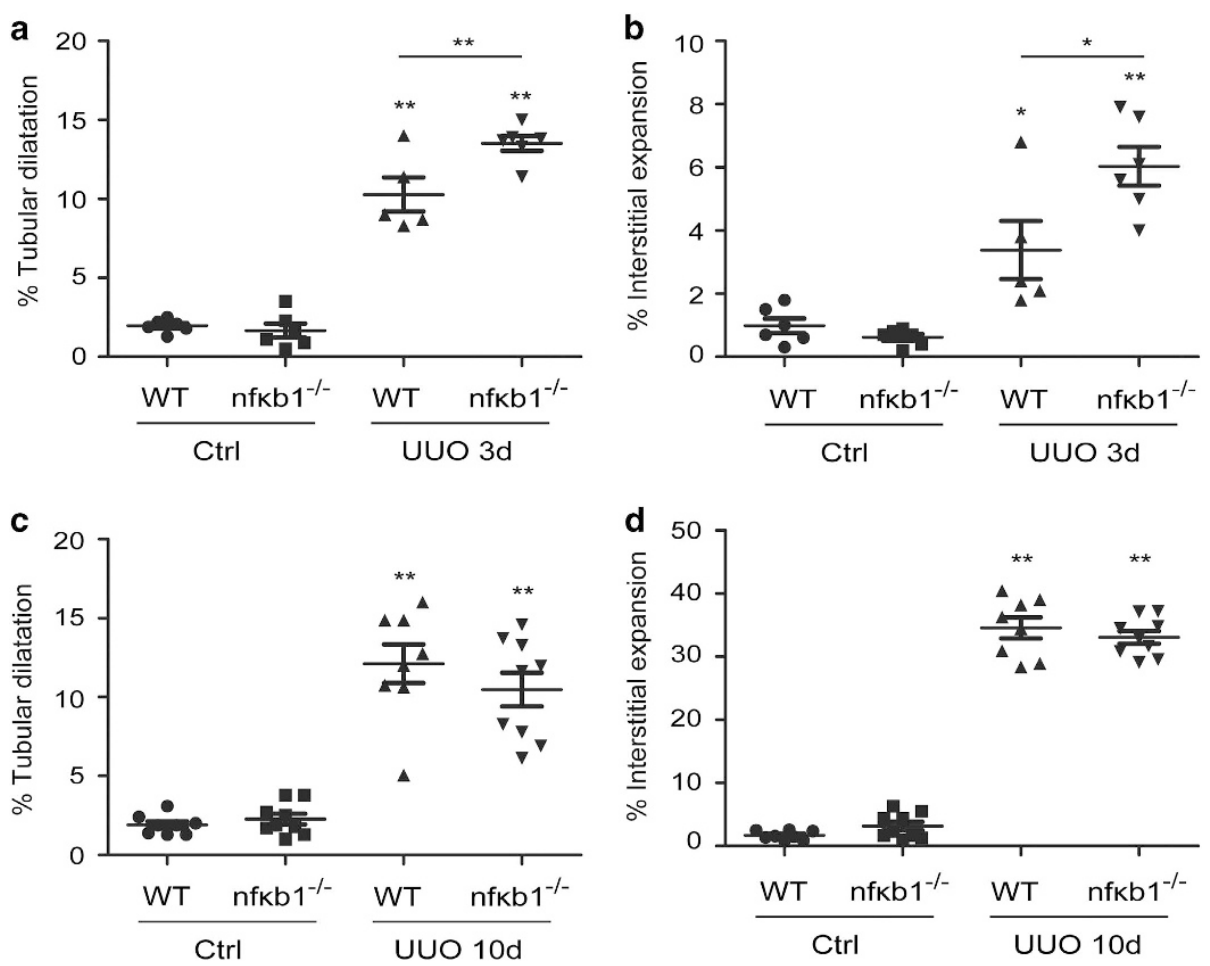

Figure $8 \mathrm{NF}-\kappa \mathrm{B} 1$-deficient mice show greater tubular dilation and interstitial expansion during the inflammatory phase of UUO. Percentage score of tubular dilatation and interstitial expansion in kidney tissue from WT and $n f \kappa b 1^{-1-}$ controls, 3 days $(\mathbf{a}, \mathbf{b})$ or 10 days $(\mathbf{c}, \mathbf{d})$ UUO. $N=6$, one way ANOVA, ${ }^{*} P \leqslant 0.05$ or ${ }^{\star \star} P \leqslant 0.01$

The pro-inflammatory activity of $\mathrm{NF}-\kappa \mathrm{B}$ has made it an attractive option for drug targeting. Therapeutic and pre-clinic efficacy has been shown in models of rheumatoid arthritis and inflammatory bowel disease. ${ }^{28}$ However, according to our results, future therapeutic approaches targeting NF- $k B$ will need to carefully consider the protective functions of the NF- $k \mathrm{~B}$ subunit p50 (NF-kB1) during the onset of acute renal injury.

\section{Materials and Methods}

Animal models of renal disease. All animals were used in accordance with UK Home Office regulations and the Animals (Scientific Procedures) Act 1986. Nfkb1 ${ }^{-1}-$ mice $^{29}$ were bred as homozygous lines and compared with C57BL/6 WT mice. NTS nephritis was induced in WT, $n f \kappa b 1^{-1-}$ or chimeric mice by tail vein injection of $200 \mu \mathrm{l}$ of NTS containing $0.5 \mathrm{ng} / \mu \mathrm{l}$ LPS. $^{30}$ Controls were tail veininjected with equivalent volume of saline. Kidneys were harvested $2 \mathrm{~h}, 24 \mathrm{~h}$ or 7 days after injection. Mice were housed in metabolic cages for $24 \mathrm{~h}$ pre and postNTS injection. Unilateral ureteric obstruction (UUO) was performed in WT and nfk $\mathrm{b}^{-1-}$ mice as described previously. ${ }^{31,32}$ Kidneys were harvested at 3 and 10 days post-UUO. A minimum of 6 animals were used in each experimental group.

Generation of bone marrow chimeras. Bone marrow cells were harvested from the femurs of donor mice using standard techniques. Recipient mice were irradiated (10 Gy) and after $4 \mathrm{~h}$ injected with $10^{7}$ donor bone marrow cells. After 6 weeks conversion was assessed by PCR on genomic DNA isolated from blood prior to induction of NTS nephritis for $24 \mathrm{~h}$. After mice were killed bone marrow was harvested to assess the presence of NF- $\kappa \mathrm{B} p 50$ protein in cell lysates by western blot (Supplementary Figure $3 \mathrm{~A}$ and $\mathrm{B}$ ).

Glomerular injury score. Two micron sections of formalin fixed, wax embedded kidneys were stained with Periodic Acid Schiff (PAS) following standard procedure. Infiltrating neutrophils in the glomeruli were identified by their typical nuclear morphology. ${ }^{33}$ Glomerular thrombosis was blindly scored as ' 0 ' (no injury), ' 1 ' (<25\% injury), ' 2 ' (25-50\% injury), ' 3 ' (50-75\% injury) and '4' (75-100\% injury). ${ }^{34}$ At least 15 glomeruli (2 h NTS) or 30 glomeruli (24 h NTS) were counted per section.

Biochemical analysis. Blood urea nitrogen (BUN) was performed in the Clinical Biochemistry department, Newcastle upon Tyne Hospitals NHS Foundation Trust.

Measurement of urinary albumin concentration. Urine albumin concentration was measured by radial immunodiffusion in 1.2\% agarose gels containing $150 \mu \mathrm{l}$ of rabbit anti-mouse albumin antibody (Abcam, Cambridge, UK) per $10 \mathrm{ml}$ of gel. The diameter of precipitation rings was measured using UTHSCSA Image Tool 3.0 computer software (University of Texas Health Science Centre, San Antonio) and urinary albumin concentrations calculated from known standards.

Interstitial expansion and tubular dilation analysis. For the UUO kidneys analysis of interstitial expansion and tubular dilatation was performed by superimposing a $10 \times 10$ grid over each of 20 non-overlapping $250 \times$ cortical images for each section. Intersections overlaying either interstitial space or tubular luminae were counted and expressed as a percentage of the total area containing 81 grid intersections.

Immunohistochemical staining and analysis. Immunohistochemistry was performed in $4 \mu \mathrm{m}$ formalin-fixed kidney slides. Sections were deparaffinised and endogenous peroxidase was blocked with $2 \%$ hydrogen peroxide/methanol. Pronase, Proteinase $\mathrm{K}$ and heat mediated sodium citrate antigen retrieval was performed for NIMP, F4/80 and C3 staining respectively. Afterwards endogenous avidin and biotin were blocked. Blocking solution and primary antibody was added overnight (NIMP, F4/80 and C3 from Abcam). After the addition of secondary biotinylated antibody and $A B C$, sections were developed with $D A B$, counterstain with Mayer's haematoxylin and mounted with Pertex. NIMP+ cells were manually counted in at least 15 random glomeruli per section. F4/80 and C3 morphometric image analysis was performed at $400 \times$ using Nikon Eclipse Upright microscope and NIS-Elements BR Analysis software from Nikon. At least 10 random glomeruli were analysed per kidney and data is expressed as percentage of positive staining per glomeruli. 
Immunofluorescent staining. Kidney sections were deparaffinized and hydrated. Proteinase $\mathrm{K}$ antigen retrieval was performed. Blocking solution was added followed by F4/80 antibody (Abcam) overnight. After washing, secondary Alexa Fluor 568 was added and slides were mounted with Prolong mounting medium. Image analysis was performed with a Zeiss Axioimager Apotome microscope and Image J Software (National Institute of Health, USA). Data is expressed as average mean fluorescence intensity in the glomeruli.

NTS glomerular binding assessment. Glomerular binding of NTS was visualised using FITC conjugated donkey anti-sheep antibody on unfixed kidney cryosections blocked with $5 \%$ horse serum. Slides were imaged using a Leica LMD microscope. Fluorescence intensity was analysed using Image $\mathrm{J}$ software.

Mesangial cell isolation and culture. Mesangial cells were isolated as described before. ${ }^{35}$ Briefly, WT or nfkb $1^{-1-}$ kidney cortex was mince and passed through $100 \mu \mathrm{m}$ followed by $40 \mu \mathrm{m}$ cell strainers. The material that would not pass through the strainer was collected, centrifuged and the pellet was digested with collagenase IV for 10 min at $37^{\circ} \mathrm{C}$. Glomeruli cell outgrowths were passaged four times before obtaining mesangial cells. Mesangial cells were culture in RPMl 1640, supplemented with $10 \% \mathrm{FBS}, 100 \mathrm{U} / \mathrm{ml}$ penicillin, $100 \mu \mathrm{g} / \mathrm{ml}$ streptomycin and $1 \%$ insulin, transferrin, selenium and maintained at $37^{\circ} \mathrm{C}$ at an atmosphere of $5 \% \mathrm{CO}_{2}$.

Bone marrow-derived macrophage isolation and culture. Bone marrow cells were isolated from femurs of WT or nfkb $1^{-1-}$ mice and differentiated into macrophages as described previously. ${ }^{21}$ Cells were serum starved before treating them with $100 \mathrm{ng} / \mathrm{ml}$ of LPS for 2, 4, 6 and $24 \mathrm{~h}$ or $50 \mathrm{ng} / \mathrm{ml}$ of TNF- $\alpha$ for $10,30,60$ and $120 \mathrm{~min}$.

Measurement of oxidative burst. The oxidative burst in leukocytes was measured in heparinized whole blood from WT and nfkb1 ${ }^{-1-}$ mice using Phagoburst kit (Glicotope Biotechnology) according to manufacturer's instructions. Using flow cytometry this kit allows the detection of percentage of phagocytic cells which produce reactive oxidants (conversion of DHR123 to R123) and their enzymatic activity (amount of R123 per cell) against several stimuli opsonized bacteria (E. coll), Phorbol 12-myristate 13-acetate (PMA) and N-Formyl-Met-LeuPhe (fMLP).

Analysis of gene expression. Total RNA was isolated from homogenised renal cortex by standard chloroform extraction followed by isopropanol precipitation. cDNA was synthesised from $250 \mathrm{ng}$ of total RNA. Real time PCR was performed with SYBR Green JumpStart ready mix according to manufacturer's instructions. Data was calculated using $\triangle \triangle \mathrm{Ct}$ and GAPDH was used as a housekeeping gene. Data is plotted against WT control group. Primer sequences used are listed in the Supplementary Table 1.

Statistical analysis. Results are expressed as mean \pm S.E.M. unless otherwise stated in the figure legend. All $P$ values were calculated using one way ANOVA followed by Bonferroni's test or two-tailed unpaired student's $t$-test. ${ }^{*} P \leqslant 0.05$ or ${ }^{* *} P \leqslant 0.01$ was considered statistically significant.

\section{Conflict of Interest}

The authors declare no conflict of interest.

Acknowledgements. P50 deficient nfkb1 $1^{-/-}$mice were a gift from Professor DA Mann, Newcastle University. This work was funded by Northern Counties Kidney Research Fund (NCKRF), Wellcome Trust Institutional Strategic Support schemes and MRC Confidence in Concept funds granted to AM. This work was also funded by the cross-council Lifelong Health and Wellbeing initiative which is managed by the MRC (award reference i L016354). CF and AM salaries were funded through NIHR Newcastle Biomedical Research Centre and Newcastle University NURF's scheme respectively. GRS is funded by Indonesia Endowment Fund for Education.

1. Jha V, Garcia-Garcia G, Iseki K, Li Z, Naicker S, Plattner B et al. Chronic kidney disease: global dimension and perspectives. Lancet 2013; 382: 260-272.

2. Galjee MA, Visser FC, De Cock CC, Eenige, Van MJ. The prognostic value, clinical, and angiographic characteristics of patients with early postinfarction angina after a first myocardial infarction. Am Heart J 1993; 125: 48-55.
3. Hayden MS, Ghosh S. NF-kappaB, the first quarter-century: remarkable progress and outstanding questions. Genes Dev 2012; 26: 203-234.

4. Bours V, Franzoso G, Azarenko V, Park S, Kanno T, Brown K et al. The oncoprotein Bcl-3 directly transactivates through kappa $B$ motifs via association with DNA-binding p50B homodimers. Cell 1993; 72: 729-739.

5. Paz-Priel I, Houng S, Dooher J, Friedman AD. C/EBPalpha and C/EBPalpha oncoproteins regulate nfkb1 and displace histone deacetylases from NF-kappaB p50 homodimers to induce NF-kappaB target genes. Blood 2011; 117: 4085-4094.

6. Carmody RJ, Ruan Q, Palmer S, Hilliard B, Chen YH. Negative regulation of toll-like receptor signaling by NF-kappaB p50 ubiquitination blockade. Science 2007; 317: 675-678.

7. Cao S, Zhang X, Edwards JP, Mosser DM. NF-kappaB1 (p50) homodimers differentially regulate pro- and anti-inflammatory cytokines in macrophages. J Biol Chem 2006; 281: 26041-26050.

8. Sanz AB, Sanchez-Nino MD, Ramos AM, Moreno JA, Santamaria B, Ruiz-Ortega M et al. NF-kappaB in renal inflammation. J Am Soc Nephrol 2010; 21: 1254-1262.

9. Zhang H, Sun SC. NF-kappaB in inflammation and renal diseases. Cell Biosci 2015; 5: 63.

10. Karkar AM, Koshino Y, Cashman SJ, Dash AC, Bonnefoy J, Meager A et al. Passive immunization against tumour necrosis factor-alpha (TNF-alpha) and IL-1 beta protects from LPS enhancing glomerular injury in nephrotoxic nephritis in rats. Clin Exp Immunol 1992; 90: 312-318.

11. Ryffel B, Eugster $\mathrm{H}$, Haas $\mathrm{C}$, Le Hir M. Failure to induce anti-glomerular basement membrane glomerulonephritis in TNF alpha/beta deficient mice. Int J Exp Pathol 1998; 79: 453-460.

12. Horii $Y$, Iwano M, Hirata $E$, Shiiki M, Fujii $Y$, Dohi $K$ et al. Role of interleukin-6 in the progression of mesangial proliferative glomerulonephritis. Kidney Int Suppl 1993; 39: S71-S75.

13. Pepper RJ, Wang HH, Rajakaruna GK, Papakrivopoulou E, Vogl T, Pusey CD et al. S100A8/ A9 (calprotectin) is critical for development of glomerulonephritis and promotes inflammatory leukocyte-renal cell interactions. Am J Pathol 2015; 185: 1264-1274.

14. Lawrence $T$, Fong $C$. The resolution of inflammation: anti-inflammatory roles for NF-kappaB. Int J Biochem Cell Biol 2010; 42: 519-523.

15. Gomez-Guerrero C, Hernandez-Vargas P, Lopez-Franco O, Ortiz-Munoz G, Egido J. Mesangial cells and glomerular inflammation: from the pathogenesis to novel therapeutic approaches. Curr Drug Targets Inflamm Allergy 2005; 4: 341-351.

16. Artis D, Kane CM, Fiore J, Zaph C, Shapira S, Joyce K et al. Dendritic cell-intrinsic expression of NF-kappa B1 is required to promote optimal Th2 cell differentiation. J Immunol 2005; 174: 7154-7159.

17. Tomczak MF, Gadjeva M, Wang YY, Brown K, Maroulakou I, Tsichlis PN et al. Defective activation of ERK in macrophages lacking the p50/p105 subunit of NF-kappaB is responsible for elevated expression of IL-12 p40 observed after challenge with Helicobacter hepaticus. $\mathrm{J}$ Immunol 2006; 176: 1244-1251.

18. Mezzano S, Aros C, Droguett A, Burgos ME, Ardiles L, Flores $C$ et al. NF-kappaB activation and overexpression of regulated genes in human diabetic nephropathy. Nephrol Dial Transplant 2004; 19: 2505-2512.

19. Sakai N, Wada T, Furuichi K, Iwata Y, Yoshimoto K, Kitagawa $K$ et al. p38 MAPK phosphorylation and NF-kappa B activation in human crescentic glomerulonephritis. Nephrol Dial Transplant 2002; 17: 998-1004.

20. Zheng L, Sinniah R, Hsu SI. In situ glomerular expression of activated NF-kappaB in human lupus nephritis and other non-proliferative proteinuric glomerulopathy. Virchows Archiv2006; 448: 172-183.

21. Wilson CL, Jurk D, Fullard N, Banks P, Page A, Luli $S$ et al. NFkappaB1 is a suppressor of neutrophil-driven hepatocellular carcinoma. Nat Commun 2015; 6: 6818.

22. Cao C, Wang S, Fan L, Wan X, Liu X, Chen X. Renal protection by ischemic preconditioning is associated with p50/p50 homodimers. Am J Nephrol 2010; 31: 1-8.

23. Panzer U, Steinmetz OM, Turner JE, Meyer-Schwesinger C, von Ruffer C, Meyer TN et al. Resolution of renal inflammation: a new role for NF-kappaB1 (p50) in inflammatory kidney diseases. Am J Physiol Renal Physiol 2009; 297: F429-F439.

24. Karin M. Mitogen activated protein kinases as targets for development of novel antiinflammatory drugs. Annal Rheumat Dis 2004; 63: ii62-ii64.

25. Yang HT, Wang Y, Zhao X, Demissie E, Papoutsopoulou S, Mambole A et al. NF-kappaB1 inhibits TLR-induced IFN-beta production in macrophages through TPL-2-dependent ERK activation. J Immunol 2011; 186: 1989-1996.

26. Waterfield MR, Zhang M, Norman LP, Sun SC. NF-kappaB1/p105 regulates lipopolysaccharide-stimulated MAP kinase signaling by governing the stability and function of the Tpl2 kinase. Mol Cell 2003; 11: 685-694.

27. Hocherl K, Schmidt C, Kurt B, Bucher M. Inhibition of NF-kappaB ameliorates sepsisinduced downregulation of aquaporin-2/V2 receptor expression and acute renal failure in vivo. Am J Physiol Renal Physiol 2010; 298: F196-F204.

28. Roman-Blas JA, Jimenez SA. NF-kappaB as a potential therapeutic target in osteoarthritis and rheumatoid arthritis. Osteoarthritis Cartilage 2006; 14: 839-848.

29. Sha WC, Liou HC, Tuomanen El, Baltimore D. Targeted disruption of the p50 subunit of NF-kappa B leads to multifocal defects in immune responses. Cell 1995; 80: 321-330.

30. Brown HJ, Lock HR, Wolfs TG, Buurman WA, Sacks SH, Robson MG. Toll-like receptor 4 ligation on intrinsic renal cells contributes to the induction of antibodymediated glomerulonephritis via CXCL1 and CXCL2. J Am Soc Nephrol 2007; 18: 1732-1739. 
31. Fox C, Cocchiaro P, Oakley F, Howarth R, Callaghan $\mathrm{K}$, Leslie J et al. Inhibition of lysosomal protease cathepsin D reduces renal fibrosis in murine chronic kidney disease. Sci Rep 2016; 6: 20101.

32. Chowdhury P, Sacks SH, Sheerin NS. Endogenous ligands for TLR2 and TLR4 are not involved in renal injury following ureteric obstruction. Nephron Exp Nephrol 2010; 115: e122-e130.

33. Sheerin NS, Springall T, Carroll MC, Hartley B, Sacks SH. Protection against anti-glomerular basement membrane (GBM)-mediated nephritis in C3- and C4-deficient mice. Clin Exp Immunol 1997; 110: 403-409.

34. Cook HT, Ebrahim H, Jansen AS, Foster GR, Largen P, Cattell V. Expression of the gene for inducible nitric oxide synthase in experimental glomerulonephritis in the rat. Clin Exp Immunol 1994; 97: 315-320.

35. Brown HJ, Lock HR, Sacks SH, Robson MG. TLR2 stimulation of intrinsic renal cells in the induction of immune-mediated glomerulonephritis. J Immunol 2006; 177: 1925-1931. (c) (1) Cell Death and Disease is an open-access journal published by Nature Publishing Group. This work is licensed under a Creative Commons Attribution 4.0 International License. The images or other third party material in this article are included in the article's Creative Commons license, unless indicated otherwise in the credit line; if the material is not included under the Creative Commons license, users will need to obtain permission from the license holder to reproduce the material. To view a copy of this license, visit http://creativecommons.org/licenses/by/4.0/

(C) The Author(s) 2017

Supplementary Information accompanies this paper on Cell Death and Disease website (http://www.nature.com/cddis) 